\title{
COVID-19 Mobile Apps: A Systematic Review of the Literature
}

Haridimos Kondylakis $^{1^{*}}, \mathrm{MSc}_{\mathrm{PhD}}$; Dimitrios G Katehakis ${ }^{2^{*}}, \mathrm{MS}$; Angelina Kouroubali ${ }^{1^{*}}, \mathrm{PhD}$; Fokion Logothetidis ${ }^{2^{*}}$, MBA; Andreas Triantafyllidis ${ }^{3^{*}}, \mathrm{PhD}$; Ilias Kalamaras ${ }^{3 *}, \mathrm{PhD}$; Konstantinos Votis ${ }^{3 *}, \mathrm{PhD}$; Dimitrios Tzovaras ${ }^{3^{*}}, \mathrm{PhD}$

${ }^{1}$ Computational Biomedicine Laboratory, Foundation for Research and Technology - Hellas-Institute of Computer Science, Heraklion, Greece

${ }^{2}$ Center for eHealth Applications and Services, Foundation for Research and Technology - Hellas, Institute of Computer Science, Heraklion, Greece

${ }^{3}$ Information Technologies Institute, Centre for Research and Technology - Hellas, Thessaloniki, Greece

*all authors contributed equally

\section{Corresponding Author:}

Haridimos Kondylakis, MSc, $\mathrm{PhD}$

Computational Biomedicine Laboratory

Foundation for Research and Technology - Hellas-Institute of Computer Science

N. Plastira 100

Heraklion, 70013

Greece

Phone: 302810391449

Email: kondylak@ics.forth.gr

\section{Abstract}

Background: A vast amount of mobile apps have been developed during the past few months in an attempt to "flatten the curve" of the increasing number of COVID-19 cases.

Objective: This systematic review aims to shed light into studies found in the scientific literature that have used and evaluated mobile apps for the prevention, management, treatment, or follow-up of COVID-19.

Methods: We searched the bibliographic databases Global Literature on Coronavirus Disease, PubMed, and Scopus to identify papers focusing on mobile apps for COVID-19 that show evidence of their real-life use and have been developed involving clinical professionals in their design or validation.

Results: Mobile apps have been implemented for training, information sharing, risk assessment, self-management of symptoms, contact tracing, home monitoring, and decision making, rapidly offering effective and usable tools for managing the COVID-19 pandemic.

Conclusions: Mobile apps are considered to be a valuable tool for citizens, health professionals, and decision makers in facing critical challenges imposed by the pandemic, such as reducing the burden on hospitals, providing access to credible information, tracking the symptoms and mental health of individuals, and discovering new predictors.

(J Med Internet Res 2020;22(12):e23170) doi: 10.2196/23170

\section{KEYWORDS}

mobile apps; systematic survey; COVID-19; mobile health; eHealth

\section{Introduction}

The COVID-19 outbreak, which first emerged in China, has spread worldwide. On March 11, 2020, the World Health Organization (WHO) declared COVID-19 as a pandemic [1]. The disease has disrupted global trade, employment, and travel, and many governments had to take strict measures to control the spread of the virus and minimize the burden of morbidity and mortality so that health care systems remain functional [2]. In many countries around the world, citizens have been recommended to stay at home and practice social distancing for as long as possible as a primary measure of preventing the spread of COVID-19.

Although mobile apps are successfully used for managing chronic diseases $[3,4]$, the ongoing COVID-19 pandemic has pushed the need for mobile app solutions at the forefront to reduce the risk of cross-contamination caused by close contact [5-7]. Mobile technology has been leveraged in a number of ways to control the spread of COVID-19. Mobile apps are accessible, acceptable, and easily adopted, and have the ability to support social distancing efforts. As such, they have been widely developed and implemented during the previous months 
in an attempt to "flatten the curve" of the increasing number of COVID-19 cases, providing knowledge and information to civilians while attempting to relieve the pressure from health care systems.

Despite increasing reliance on mobile health (mHealth) solutions as part of COVID-19-related response plans, major knowledge gaps exist about their utility and efficacy during the current pandemic for both health professionals as well as for the general population. To this direction, this systematic review aims to shed light into studies found in the scientific literature on the use and evaluation of mobile apps for the prevention, management, treatment, or follow-up of COVID-19.

Other recent reviews have focused merely on the exploration of COVID-19 mobile apps in app stores in general [8] or were restricted to apps deployed in specified countries such as the United States, the United Kingdom, and India [9]. Although there are already related generic COVID-19 information and communication technology surveys $[10,11]$, they focus on specific topics such as contact tracing [12,13]; specialized health sectors like pediatric health care delivery [14], mental health [15], epilepsy [16], and palliative care [17]; or countries like India [14], China [18], and the United Kingdom [19]. To the best of our knowledge, there has been no other work dedicated to the systematic review of pragmatic studies that have demonstrated the real-life use and evaluation of COVID-19 mobile apps.

\section{Methods}

\section{Search Strategy}

The bibliographic databases of PubMed and Scopus, along with the global research database on COVID-19 developed by the WHO [20], were searched to identify mHealth apps used for the purposes of prevention, treatment, or management of COVID-19 and assessed in pragmatic studies.

\section{Eligibility Criteria}

In this context, the inclusion criteria for study selection were the following: features of the COVID-19 mobile app should be described, the study should show evidence of the implementation of the COVID-19 mobile app in real life and provide quantitative outcomes, the study should show that clinical professionals were involved in the design or validation of the mobile app, the paper describing the study must have been written in English. Case reports, letters to editors, preprint papers, qualitative studies, surveys or reviews, simulation studies, and studies describing protocols were excluded from the review.

\section{Study Selection}

The string “(mobile health) OR (mhealth) OR (smartphone) OR (mobile phone) OR (mobile application) OR (mobile app) OR (app) AND (COVID-19)," was used for a search within the title, abstract, and keywords of the manuscripts. Authors HK, AT, AK, FL, DGK, and IK independently screened the identified papers to minimize possible errors and bias in the selection process. Any disagreements were resolved by discussion between the authors to reach consensus. The authors first screened the abstracts of the candidate papers for inclusion and assessed their eligibility according to the defined inclusion and exclusion criteria. Moreover, the authors selected the final papers for inclusion after reading the full manuscripts of the eligible papers, as well as their references.

The Effective Public Health Practice Project (EPHPP) tool was adopted to assess the methodological quality of the included studies. The EPHPP tool is suitable for evaluating quantitative studies in a wide range of health-related topics, and it has demonstrated reliability [21]. The included studies were synthesized (by HK, AK, FL, and DGK) according to their target, mobile app main features, study design, number of enrolled participants and their age, follow-up duration, outcomes and whether these were positive or negative, and implications for clinical practice. This systematic review was conducted following the PRISMA (Preferred Reporting Items for Systematic Reviews and Meta-Analyses) guidelines [22]. A completed PRISMA checklist is shown in Multimedia Appendix 1 .

\section{Results}

\section{Statistical Analysis}

Our last search in June 2020 returned 165 manuscripts from the PubMed database, 188 manuscripts from the Scopus database, and another 375 manuscripts from the WHO research database. All the retrieved records were imported in the Zotero bibliography management software (Center for History and New Media at George Mason University), which identified 252 duplicates. We screened the abstracts of the remaining 476 papers according to our inclusion and exclusion criteria, and 22 papers were found to be eligible. After reading the full text of the papers, the authors agreed to include 12 papers. The screening procedure along with reasons for excluding papers are shown in the PRISMA flow diagram in Figure 1. 
Figure 1. The PRISMA (Preferred Reporting Items for Systematic Reviews and Meta-Analyses) flow diagram. WHO: World Health Organization.

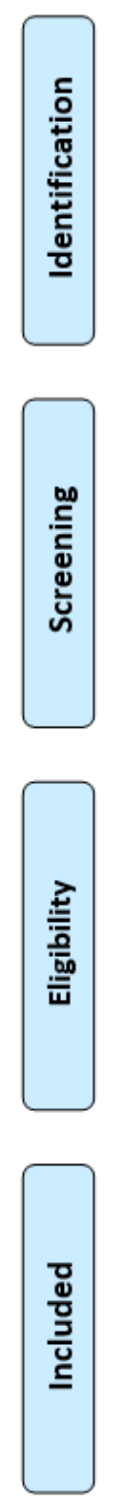

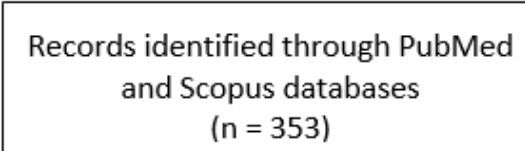

Additional records identified through WHO COVID-19 research database

$$
(n=375)
$$

\section{Study Outcomes and Quality Assessment}

On the basis of the EPHPP criteria for selection bias, design, confounders, blinding, data collection, and dropouts, we found the methodological quality to be moderate for 2 of the $12(17 \%)$ studies [23,24] and weak for the remaining 10 (83\%) studies (Table 1). Most studies were poorly rated because of their observational or cross-sectional nature, insufficient care in controlling for confounders, insufficient reporting on the validity and reliability of the tools used for data collection, and the absence of description on withdrawals and dropouts. The design of a randomized or controlled clinical trial was not reported in any of the reviewed studies. 
Table 1. Quality assessment of included studies based on the EPHPP criteria.

\begin{tabular}{|c|c|c|c|c|c|c|c|}
\hline \multirow[t]{2}{*}{ Study } & \multicolumn{6}{|c|}{ EPHPP $^{\mathrm{a}}$ criteria } & \multirow[t]{2}{*}{ Global rating } \\
\hline & $\mathrm{SB}^{\mathrm{b}}$ & $\mathrm{SD}^{\mathrm{c}}$ & $\mathrm{CF}^{\mathrm{d}}$ & $\mathrm{BL}^{\mathrm{e}}$ & $D C^{f}$ & $W^{g}$ & \\
\hline Bae et al [25] & $\mathrm{W}^{\mathrm{h}}$ & $\mathrm{W}$ & W & $M^{i}$ & $\mathrm{~W}$ & W & W \\
\hline Bourdon et al [23] & M & M & M & M & M & W & M \\
\hline Drew et al [26] & W & W & W & M & W & W & W \\
\hline Ben Hassen et al [27] & $\mathrm{W}$ & $\mathrm{W}$ & $\mathrm{W}$ & M & $S^{j}$ & W & W \\
\hline Huckins et al [24] & $\mathrm{W}$ & M & M & M & M & S & M \\
\hline Kodali et al [28] & $\mathrm{W}$ & $\mathrm{W}$ & W & M & W & W & W \\
\hline Medina et al [29] & M & W & W & M & W & W & W \\
\hline Menni et al [30] & W & $\mathrm{W}$ & S & M & W & W & W \\
\hline Ros and Neuwirth [31] & M & W & $\mathrm{W}$ & M & W & W & W \\
\hline Timmers et al [32] & M & M & $\mathrm{W}$ & M & W & W & W \\
\hline Yamamoto et al [33] & M & W & W & M & W & W & W \\
\hline Zamberg et al [34] & W & W & W & $\mathrm{M}$ & W & W & W \\
\hline
\end{tabular}

${ }^{a}$ EPHPP: Effective Public Health Practice Project.

${ }^{\mathrm{b}} \mathrm{SB}$ : selection bias.

${ }^{\mathrm{c}} \mathrm{SD}$ : study design.

${ }^{\mathrm{d}} \mathrm{CF}$ : confounders.

${ }^{\mathrm{e}} \mathrm{BL}$ : blinding.

fDC: data collection methods.

${ }^{g}$ WD: withdrawals and dropouts.

${ }^{\mathrm{h}} \mathrm{W}$ : weak.

${ }^{\mathrm{i}} \mathrm{M}$ : moderate.

${ }^{\mathrm{j}} \mathrm{S}$ : strong.

\section{Comparison}

In the following sections, we provide a comparison of the included studies, in terms of intervention target and main features, study design, and outcome and clinical implications.

\section{Intervention Target and Main Features}

The reviewed papers varied in intervention target and main features (Table 2). One paper discussed a COVID-19 tracking app informing users about risk assessment and offering relevant advice [28]. The paper did not provide further details about app features. Apps that offered education and information material were discussed in 3 papers. They either targeted patients or

health care professionals. Patient education included hospital information (appointments, visiting hours, self-isolation, and general COVID-19 information [32]) and education related to SARS-CoV-2. For health care professionals, they included information about how to handle patients with COVID-19 $[31,34]$. One paper [25] described how the hospital information system was adapted to handle COVID-19 with the incorporation of relevant templates. An app for recording general health information was discussed in 1 paper [33], and apps for self-assessment focusing on symptoms were found in 1 paper [32]. Self-monitoring based on a symptom diary and health observation data were also reported in 4 papers $[26,29,32,33]$. 
Table 2. A comparison of intervention target and main features.

\begin{tabular}{lll}
\hline Studies & Intervention & Main features \\
\hline Kodali et al [28] & Tracking app & Risk assessment and advice \\
Timmers et al [32] & Education and information & Information for patients \\
Ros and Neuwirth [31] and Zamberg et al [34] & Education and information & Information for health care professionals \\
Bourdon et al [23] & Hospital information system & Adaptation to pandemic \\
Yamamoto et al [33] & Health assessment & General \\
$\begin{array}{l}\text { Bae et al [25], Medina et al [29], Timmers et al [32], } \\
\text { and Yamamoto et al [33] }\end{array}$ & Health assessment & Self-monitoring \\
Medina et al [29] & Home monitoring & Telephone outreach \\
Bourdon et al [23] & Home monitoring & Vital signs with smart devices \\
Drew et al [26] & Home monitoring & Internet of Things \\
Timmers et al [32] & Interactive map & Demographics and health status \\
Yamamoto et al [33] & Data sharing & Patient email to specific recipients \\
Medina et al [29] & Data sharing & Nurse outreach \\
Ben Hassen et al [27] & Student mental health & Behavior during the pandemic \\
Menni et al [30] & Prediction model & Progress of disease \\
Huckins et al [24] & Teleophtalmology & Emergency eye care
\end{tabular}

Home monitoring was handled based on telephone outreach [29], smart vital sign monitoring devices [25], and Internet of Things [27]. An interactive map of user demographics and health status was discussed in 1 paper [32]. Two apps offered data sharing capabilities via email to specific recipients based on patient options [33], or as symptoms were worsening, the app sent messages to be assessed by nursing staff to provide appropriate advice [29]. One paper assessed student behavior to determine whether the mental health of participants changed due to the COVID-19 pandemic [24]. One paper used data collected by Drew et al [26] to develop a prediction model about disease progress as well as tracking the disease progress in real time [30]. Finally, 1 paper [23] reported on a smartphone app to manage emergency eye care.

\section{Study Design and Structure of Research}

Regarding the study design, almost all selected studies were proof of concept, observational studies, or both, aiming to evaluate the practical use, usability, or user satisfaction with the corresponding apps that were developed to support individuals, health care providers, and policy makers during the COVID-19 pandemic (Table 3). 
Table 3. A comparison of study design and structure of the research.

\begin{tabular}{|c|c|c|c|c|}
\hline Study & Study design & Participants, $\mathrm{n}$ & Age & $\begin{array}{l}\text { Follow-up duration } \\
\text { (study period) }\end{array}$ \\
\hline $\begin{array}{l}\text { Bourdon et al } \\
\text { [23] }\end{array}$ & $\begin{array}{l}\text { Online surveys on patient and medical staff satisfaction } \\
\text { with the mobile app and the wearables }\end{array}$ & $\begin{array}{l}12 \text { patients and } 24 \\
\text { medical staff }\end{array}$ & $\begin{array}{l}\text { Patient mean age: } 25 \\
\text { years; no information } \\
\text { for medical staff }\end{array}$ & No follow-up \\
\hline $\begin{array}{l}\text { Huckins et al } \\
{[24]}\end{array}$ & $\begin{array}{l}\text { Observational cohort study measuring behaviors } \\
\text { through the StudentLife smartphone sensing app }\end{array}$ & 500 & $\begin{array}{l}\text { Mean: } 40.7 \text { (SD 20.3; } \\
0.6-92 \text { ) years. The } \\
\text { number of patients old- } \\
\text { er than } 60 \text { years was } \\
\text { small. }\end{array}$ & No follow-up \\
\hline Bae et al [25] & $\begin{array}{l}\text { Observational data collection that helped develop } \\
\text { predictive models. Participants that were already en- } \\
\text { rolled in ongoing epidemiologic studies were ap- } \\
\text { proached to use this app. }\end{array}$ & $\begin{array}{l}>2 \text { million users; } 75 \% \\
\text { female }\end{array}$ & $\begin{array}{l}\text { Mean: } 41 \text { (range: } 18- \\
\text { 90) years }\end{array}$ & $\begin{array}{l}\text { The launching of the } \\
\text { COVID Symptom } \\
\text { Study app occurred in } \\
\text { the United Kingdom on } \\
\text { March } 24,2020 \text {, and in } \\
\text { the United States on } \\
\text { March } 29,2020 \text {. } \\
265,851 \text { individuals } \\
\text { were enrolled by March } \\
27,2020 \text {. }\end{array}$ \\
\hline Drew et al [26] & $\begin{array}{l}\text { Observational study on the COVID Symptom Tracker } \\
\text { mobile app }\end{array}$ & $\begin{array}{l}5 \text { hospitalized patients } \\
\text { and } 5 \text { doctors }\end{array}$ & $\begin{array}{l}\text { Patients range: } 45-61 \\
\text { years }\end{array}$ & No follow-up \\
\hline $\begin{array}{l}\text { Ben Hassen et } \\
\text { al [27] }\end{array}$ & $\begin{array}{l}\text { The StudentLife app was used for smartphone mobile } \\
\text { sensing. Ecological momentary assessments were used } \\
\text { to assess depression and anxiety. }\end{array}$ & $\begin{array}{l}217 ; 67.8 \%(n=147) \\
\text { were female }\end{array}$ & $\begin{array}{l}\text { Range: } 18-22 \text { years at } \\
\text { the time of enrollment }\end{array}$ & $\begin{array}{l}178(82.0 \%) \text { students } \\
\text { provided data during } \\
\text { the Winter } 2020 \text { term } \\
\text { (January } 6 \text { to March } 13 \text {, } \\
\text { 2020). }\end{array}$ \\
\hline $\begin{array}{l}\text { Kodali et al } \\
{[28]}\end{array}$ & $\begin{array}{l}\text { Observational study using descriptive statistics and } \\
\text { thematic analysis on the mHealth }{ }^{\mathrm{a}} \text { app Arogya Setu. }\end{array}$ & $\begin{array}{l}503 \text { most relevant re- } \\
\text { views were identified } \\
\text { based on the Google al- } \\
\text { gorithm }\end{array}$ & Not reported & $\begin{array}{l}\text { All reviews that were } \\
\text { available publicly and } \\
\text { posted in English by the } \\
\text { users until April 21, } \\
2020 \text {, were included. } \\
\text { The start date of app re- } \\
\text { views collection was } \\
\text { not reported. }\end{array}$ \\
\hline $\begin{array}{l}\text { Medina et al } \\
{[29]}\end{array}$ & $\begin{array}{l}\text { Observational cohort study carried out at the Cleveland } \\
\text { Clinic, OH, US. It included a self-monitoring app for } \\
\text { patient engagement and early intervention. }\end{array}$ & $\begin{array}{l}\text { COVID-19 patients en- } \\
\text { rolled by May 25, 2020: } \\
\text { 1924. Most }(85 \%) \text { pa- } \\
\text { tients were enrolled } 5 \\
\text { days from symptom on- } \\
\text { set. }\end{array}$ & $\begin{array}{l}25 \%(\mathrm{n}=483) \text { were old- } \\
\text { er than } 60 \text { years, and } \\
3.5 \%(\mathrm{n}=67) \text { were } \\
\text { younger than } 18 \text { years. }\end{array}$ & $\begin{array}{l}\text { Engagement with My- } \\
\text { Care Companion app } \\
\text { reached } 32 \% ; 25 \% \text { con- } \\
\text { tinued under monitoring } \\
\text { for longer than } 14 \text { days } \\
\text { due to persistent symp- } \\
\text { toms. }\end{array}$ \\
\hline Menni et al [30] & $\begin{array}{l}\text { Observational data collection and statistical analysis } \\
\text { that helped develop predictive models }\end{array}$ & $\begin{array}{l}\text { Symptoms were report- } \\
\text { ed by } 2,450,569 \text { from } \\
\text { the UK and } 168,293 \\
\text { from the US }\end{array}$ & $\begin{array}{l}\text { Average age for tested } \\
\text { positive, tested nega- } \\
\text { tive, and not tested: } \\
\text { (UK: } 41.25,41.87 \text {, and } \\
\text { 43.38; US: } 41.87 \text {, } \\
47.25 \text {, and } 53.00 \text { ). }\end{array}$ & $\begin{array}{l}\text { Data analyzed had been } \\
\text { collected between } \\
\text { March } 24 \text { and April 21, } \\
2020 .\end{array}$ \\
\hline $\begin{array}{l}\text { Ros and } \\
\text { Neuwirth [31] }\end{array}$ & $\begin{array}{l}\text { A tutorial feedback survey was conducted. User feed- } \\
\text { back was requested from health care workers and re- } \\
\text { sponders about the presented global public health edu- } \\
\text { cational outreach technology. }\end{array}$ & $\begin{array}{l}12,516 \text { users, learners, } \\
\text { health care workers, } \\
\text { and responders down- } \\
\text { loaded the app in } 1 \\
\text { month. }\end{array}$ & Not provided & $\begin{array}{l}366 \text { replies received } \\
\text { during the first } 72 \mathrm{~h} \text { of } \\
\text { deploying the survey. } \\
\text { During this time period, } \\
\text { there were } 512 \text { sub- } \\
\text { scribers that had down- } \\
\text { loaded the app ( } 71.48 \% \\
\text { response rate). }\end{array}$ \\
\hline
\end{tabular}




\begin{tabular}{|c|c|c|c|c|}
\hline Study & Study design & Participants, $\mathrm{n}$ & Age & $\begin{array}{l}\text { Follow-up duration } \\
\text { (study period) }\end{array}$ \\
\hline $\begin{array}{l}\text { Timmers et al } \\
\text { [32] }\end{array}$ & $\begin{array}{l}\text { Observational cohort study (based on the data collected } \\
\text { at the ETZ }{ }^{\mathrm{b}} \text { hospital), assessed the use of the app as } \\
\text { well as its usability. Data were gathered for health care } \\
\text { providers and policy makers. }\end{array}$ & $\begin{array}{l}6194 \text { individuals down- } \\
\text { loaded the app. }\end{array}$ & Average: 50.87 years & $\begin{array}{l}\text { The study focused on } \\
\text { data collected between } \\
\text { April 1-20, } 2020 \text {. The } \\
\text { app was being used by } \\
\text { over } 15 \text { hospitals in the } \\
\text { Netherlands, Belgium, } \\
\text { and Germany, accumu- } \\
\text { lating over } 30,000 \\
\text { downloads. }\end{array}$ \\
\hline
\end{tabular}

Yamamoto et al Proof of concept and practical use study in a real-world [33] setting. The study aimed to develop a PHR ${ }^{\mathrm{c}}$-based COVID-19 symptom-tracking app to determine whether PHRs could be used for efficient health observation outside a traditional hospital setting. The practical aspects of health observations for COVID-19 using the smartphone or tablet app integrated with PHRs was demonstrated. Moreover, a usability evaluation of the app was carried out based on interviews with help desk managers of the app.

Zamberg et al [34]
Utilization-focused evaluation study to identify the use of an mHealth platform for information sharing
In the context of the active epidemiological investigation period (from March 6-19, 2020) at Wakayama City Public Health Center, 72 individuals who had close contact with a COVID19 confirmed case were discovered. Among them, 57 had adopted the use of the health observation app.

125 members of the hospital staff

$N / A^{d}$

25-30 years: 28 members; 31-35 years: 24 members; $36-40$ years: 18 members; 41-50 years: 29 members; 51- 2020. 60 years: 24 members; $>60$ years: 2 members
The active epidemiological investigation period was carried out from March 6-19, 2020, at Wakayama City Public Health Center. In this period 57 of 72 individuals (health observers) adopted the use of the app. By mid-May, the app had been used by more than 20,280 users and 400 facilities and organizations. These included companies, schools, hospitals, and local governments across Japan.

The mHealth platform was used for 18 days from February 25, 2020, until March 13,

\footnotetext{
amHealth: mobile health.

${ }^{b}$ ETZ: Elisabeth Twee Steden.

${ }^{\mathrm{c}}$ PHR: personal health record.

${ }^{\mathrm{d}} \mathrm{N} / \mathrm{A}$ : not applicable.
}

One study [24] used the corresponding mobile app (StudentLife app) as a tool for an ecological momentary assessment, aiming to assess depression and anxiety of college students to determine whether there was a change in behavior and mental health of participants in response to COVID-19.

The number of participants was mentioned in all selected studies. Some studies reported a relatively low numbers of participants using the corresponding app, whereas others a relatively large number of participants and users. The studies that reported the largest number of users were those described by Drew et al [26] (over 2 million users) and Menni et al [30] $(2,450,569$ users in the United Kingdom and 168,293 from the United States that had reported symptoms through the smartphone app). Studies that reported the lowest number of participants were the ones described by Bae et al [25] (12 patients and 24 medical staff) and Ben Hassen et al [27] (5 hospitalized patients and 5 doctors).
The age of participants was also reported in most of the studies except 3 [28,31,33]. The average age or age range for participants varied depending on the corresponding study.

Concerning the follow-up duration (study duration), 3 out of the 12 selected studies [23,25,27], did not report the study duration. Kodali et al [28] reported the end date but did not mention the start date of app use, Drew et al [26] reported only the start date of the app launch, Ros and Neuwirth [31] reported 3 days of app use, Yamamoto et al [33] reported 14 days, Zamberg et al [34] reported 18 days, Timmers et al [32] reported 20 days, and Huckins et al [24] reported 67 days of app use. Finally, Medina et al [29] mentioned that the engagement with the app reached $32 \%$, whereas $25 \%$ of users continued under monitoring for longer than 14 days due to persistent symptoms.

\section{Outcomes}

Outcome assessments were varied across studies. An overview is shown in Table 4. 
Table 4. A comparison of outcomes for the various studies.

\begin{tabular}{|c|c|c|}
\hline Paper & Primary outcomes & Positive/negative outcomes \\
\hline $\begin{array}{l}\text { Timmers et al } \\
\text { [32] }\end{array}$ & $\begin{array}{l}\text { - The information provided by the app satisfied the user needs. } \\
\text { - Users indicated the added-value of the symptom tracker diary to be } \\
\text { high. }\end{array}$ & $\begin{array}{l}\text { - } \\
\text { - } \\
\text { An app for inderactive map displayed the data collected } \\
\text { through the app. } \\
\text { - COVID-19 screening results produced at the hos- } \\
\text { pital were linked to app data. } \\
\text { Health care providers and policy makers could use } \\
\text { the data in developing their health care strategy } \\
\text { based on the distribution of the reported infection } \\
\text { load. }\end{array}$ \\
\hline
\end{tabular}

Yamamoto et - 72 health observers were identified who were in close contact with a al [33]

Zamberg et al [34]

Kodali et al [28]

Huckins et al [24]

Drew et al [26] confirmed case. Among them, 57 adopted the app, while 14 used telephone as a means for conducting investigations.

- Before the introduction of the app, phone interviews required more than 2 hours and four epidemiological officers for contact tracing. After the introduction of the app, only one epidemiological officer was needed to perform health observations.

- The visualization of health observation data improved the investigation efficiency and comprehensiveness. Three documents related to COVID-19 were made available to medical staff via the mobile platform.

- Information was viewed 859 times, which accounted for $35.6 \%$ of total document views.

- The number of sessions per day increased significantly in the study period (more than doubled) compared with the sessions per day in previous weeks.

- Usability evaluation: $70(83.3 \%)$ said it was easy to find information about SARS-CoV-2. On a 10-point Likert scale, the mHealth ${ }^{\mathrm{a}}$ solution scored 8.5 for time-saving and 7.6 for COVID-19 patient care assurance in daily practice.

- Mixed evidence about the use of the app but mainly optimistic
With the rise of news relevant to COVID-19, college students spent more time seated, had fewer visits, and showed increases in anxiety and depression.

- The authors did not observe a return to baseline over the break, although they observed decreases in stress and depression that paralleled the typical drop after the final examination, suggesting some resilience in the face of COVID-19.

- The app captures the dynamics of COVID-19 onset days before traditional measures such as positive tests, hospitalizations, or mortality.

- The collection emphasizes the potential usefulness of symptom monitoring in real time to help guide the allocation of resources for testing and treatment, as well as advising for tightening or loosening appropriate measures in specific areas.
- The ability of individuals to record health status on a daily basis was an important countermeasure against COVID-19.

- The use of the app improved the efficiency and completeness of the investigation process for COVID-19 cases carried out by epidemiological officers.

- Using the mHealth solution as a communication channel turned out to be effective within the organization for dissemination purposes during the pandemic.

- Daily practice was conducted by more confident and better-informed health care professionals.

- Error correction, improved data collection quality, and user privacy should be considered in mHealth apps.

- Steps must be taken to ensure the reliability of the information provided by users. Therefore, predicting multiple verification of data entered by users could be critical.

- Mobile apps can be effectively used for tracking the mental health of college students.

- With the participation of groups with underrepresented populations, the study aimed to encourage enrollment of individuals from populations that have traditionally been difficult to recruit.

- The study could capture correlations based on individual variations over time, a remarkable advantage over repetitive cross-sectional surveys that introduced significant variation between individuals. 


\begin{tabular}{ll}
\hline Paper & Primary outcomes \\
\hline Medina et al & - $\quad \begin{array}{l}\text { Mobile and home-based interventions were feasible for a wide range } \\
\text { of conditions with a related risk of poor outcome from COVID-19. }\end{array}$ \\
& Approximately $10 \%$ of the patients in active monitoring presented \\
symptoms such as shortness of breath that required escalation to a \\
virtual provider. The median time to escalation ranged between 7 and \\
8 days. \\
Patients with a pulse oximeter at home escalated a few days earlier \\
due to reduced oxygen saturation measurements before subjective \\
complaints of dyspnea. \\
2\% of patients in active supervision were eventually admitted, and 3\% \\
were readmitted for persistent COVID-19 symptoms or due to compli- \\
cations of other underlying diseases. \\
9 patients monitored at home died, either due to complications related \\
to COVID-19 or complications of another underlying disease.
\end{tabular}

Menni et al - Besides more established symptoms such as high fever and a persistent [30] cough, loss of smell and taste were possible prognostic factors for COVID-19.

- A combination of symptoms such as anosmia, fatigue, persistent cough, and loss of appetite together could identify individuals with COVID19.

Ross and - This app was considered by the users as appropriate to learn and review Neuwirth [31] skills relevant to COVID-19.

- More than $95 \%$ of respondents gave a score $\geq 5$ for skills acquisition.

- $\quad 88 \%$ of respondents said it matched their health care needs.

- $\quad 93 \%$ of the respondents stated that the app gave them a better understanding.

- $\quad 87 \%$ of the respondents felt quite or very confident about the execution of the procedures, as shown in the lessons.

- $\quad 94 \%$ of respondents said that this particular COVID-19 training program made them feel ready to care for COVID-19 patients.

- $\quad 95 \%$ of respondents would suggest the application to other users.
Positive/negative outcomes

- Mobile engagement platforms have the potential to reduce the need for caregiver communication for patients whose symptoms are mild or persistent, freeing up the health care professionals to focus on patients who need it more. $\bullet$

Physiological assessments of olfactory and taste function or nucleotide-based testing for SARSCoV-2 could not be replaced by self-reporting.

- The authors did not know if anosmia was acquired before or after other COVID-19 symptoms, or during or after the illness.
Bae et al [25] - Mobile app: usefulness showed the highest score, followed by satisfaction and perceived ease of use.

- Wearable vital sign monitoring perceived usefulness scored the highest, followed by perceived ease of use and satisfaction.

- $\quad$ For carers, there was an overall satisfaction score of 4.10/5.

Ben Hassen et - Patients and doctors alike accepted the home hospitalization system al [27] very well.

Bourdon et al [23]
Allowed doctors and patients to maintain social distance, avoiding three or four physical trips per person.
Advantage over medical videos:

- It allowed the user to live the experience of seeing through a first-person view to learn through the eyes of the expert.

- The ability for a health care professional to instantly download locally (in a smart phone) material that can be accessed at any time in real time before, during, or after patient care interactions.

- When downloaded, the end user could access and view the tutorial at any time, regardless of network signal issues.

- Allowed health care professionals to navigate on their own or to jump to sections that were of greater importance to them

- During periods of pandemics and disasters, automated exchange of information between health care institutions plays an important role in dealing more efficiently with the problem at hand.

- $\quad$ Adjustments should be made for COVID-19 patients safely.

- Vital signs had to be measured by the patients themselves.

- Video communication between patients and doctors was added.

- A physical appointment followed $27 \%$ of the teleconsultations.

- Average delay of 4.12 days between the onset of symptoms and advice, and <1 day for emergency episodes.

- There was $96 \%$ sensitivity and $95 \%$ specificity for the correct evaluation of the indication of a physical consultation and only $1.0 \%$ misdiagnoses. a mHealth: mobile health.

In most of the cases, app users were satisfied with the educational and risk assessment information provided in the mobile apps (both citizens [32] and health personnel [31,34]). They felt reassured and informed. However, there were also concerns [28] about the measures that would need to be taken to ensure the reliability of information provided to users.

In addition, 3 studies [26,30,32] showed the feasibility of the implementation and use of COVID-19 apps to support education, 
self-management, and symptom tracking through diaries. Symptom tracker apps had even identified potential predictors of COVID-19, such as loss of smell and taste [30]. To this direction, mobile app sensing revealed that, during the COVID-19 pandemic, individuals were more sedentary, visited fewer locations, and showed increases in anxiety and depression [24], which is in line with the "Stay safe, stay home" policies mandated by local and national governments. However, there were concerns that cross-verification of data entered by the users could be crucial [28] and that the self-reported nature of the data collected by these apps could not replace physiological assessments and clinical examinations [30].

Additionally, mobiles apps were used for home monitoring, as reported in 4 studies [23,25,27,29], with satisfactory usability for both patients and health care professionals. These apps were focused on the management of patients who are at high risk, the moderation of exposure risk for health care workers, and the reductions of community spread through appropriate education on home-based care for individuals who are exposed or infected.

Based on the data reported in the reviewed papers, interactive maps and dashboards could be created for the quick visualization of the status summary of patients with COVID-19 and disease spread to be used by policy makers and health care providers for decision making at regional levels [26,32,33]. In addition, the dynamics of incidence days could be effectively captured, guiding allocation of resources for testing, treatment, and lockdown recommendations [26]. Mobile apps could significantly improve the efficiency and completeness of contact tracing workflows [33].

\section{Discussion}

\section{Main Findings}

A systematic review on COVID-19 mobile apps, as used and evaluated in research studies published in the scientific literature, is presented. Our literature search returned a significant number of records (476 unique published manuscripts), despite the short time period covered (December 2019 to June 2020), thereby showing the high interest of the scientific community in the research of mobile apps for COVID-19.
Our main finding is that, despite that the current research evidence is fragmented and requires greater methodological rigor, mobile apps have been found to benefit citizens, health professionals, and decision makers in facing the COVID-19 pandemic. In particular, mobile apps can help in solving several COVID-19-related challenges by increasing the reach of reliable information to both citizens and health professionals, decreasing misinformation and confusion, tracking symptoms and mental health of citizens, home monitoring and isolation, discovering new predictors, optimizing health care resource allocation, and reducing the burden of hospitals.

The participants in the studies were mainly young and middle-aged adults. Further studies are needed that will involve older participants, who are in greater risk of developing serious complications due to COVID-19. Understanding the needs of older individuals in the COVID-19 pandemic period would be the first necessary step toward designing and developing mobile apps to encourage their physical and mental well-being [17].

Our review, in contrast to other reviews that have not examined the evaluation of COVID-19 mobile apps in pragmatic studies [8], identified that the majority of included studies were not of high methodological quality, mainly because of their observational nature. This could be justified by the fact that the COVID-19 pandemic crisis generated an international appeal for fast response and rapid development of digital health tools by the research community, which might have inevitably led to the publication of early results by observational studies. This result can be seen as complementary to other reviews [8] that report that many of those apps are of high quality, offering many functionalities and advanced user experience. Longitudinal studies with rigorous design such as randomized controlled trials are now required to systematically assess COVID-19 mobile apps and provide strong evidence of their value. However, ethical implications might arise due to possible conflicts between liberty and privacy, equity, fairness, and justice [35-37]. In this direction, health outcomes that have scarcely been used so far, such as infection rate and quality of life, could be used as primary end points.

\section{Implications for Clinical Practice}

The implications for clinical practice for each one of the discussed works is shown in detail in Textbox 1. 
Textbox 1. Implications for clinical practice.

Timmers et al [32]

- eHealth mobile apps for COVID-19 that support several functionalities such as tracking of symptoms and provision of accurate and timely information as well as self-assessment can be implemented in a short time to be used by individuals.

- Those apps provide valuable information to both governments and health care providers, since they support monitoring of patient health status and provide summary statistics regarding the progress of health.

- Such apps could be used in future outbreaks of other viruses to support all involved stakeholders.

Yamamoto et al [33]

- Such apps could be used in future outbreaks of other viruses to support all involved stakeholders.

\section{Zamberg et al [34]}

- Mobile health (mHealth) apps could help solve some of the COVID-19 challenges by providing more accurate and timely information to health care professionals. This benefit is sourced by the centralized management and storage of main, up-to-date, validated, and easily accessed information in one platform.

- mHealth apps used in health care organizations as communication tools of validated information should be assessed in the context of clinical studies, with regards to their impact on clinical outcomes.

\section{Kodali et al [28]}

- According to users, the app should be enhanced with additional functionalities including tracking of location, provision of up-to-date information on COVID-19 as well as information on areas with high/medium/low epidemiological burden, and deployment in nonmobile platforms.

\section{Huckins et al [24]}

- According to the findings, since the beginning of the COVID-19 pandemic, there has been an extended negative impact both on the physical health of individuals, resulting in an increased number of deaths, and in their mental health, resulting in changes in their behavior.

\section{Drew et al [26]}

- The research of a broader range of potential risk factors for COVID-19 results will be largely supported by the use of the app within several large epidemiology cohorts for which there are a large amount of data on lifestyle, diet and health factors, and genetic information.

- It will be useful to deploy the tool in several clinical studies, in centralized actions related to biobanking, and in health care worker monitoring programs.

\section{Medina et al [29]}

- The intervention impacts several organizational matters and provides answers regarding the following questions related to COVID-19:

- Which situations should we focus on to provide effective care to prevent patient admission to intensive care unit and mechanical support?

- How can those situations be better supported by increased patient self-reporting?

- Can we predict, based on time data, future inpatient demand?

- How can we manage not having conflicts between patient choice and availability of treatment?

\section{Menni et al [30]}

- Routine screening for COVID-19 could also include loss of sense of taste and smell. These two symptoms should also be included in the related symptom list provided by the World Health Organization.

\section{Ros and Neuwirth [31]}

- The implementation and deployment of the described digital tutorials, as an effective and swift global public health educational tool, help alleviate the burden that hospitals, health care professionals/responders, and patients face due to the COVID-19 pandemic.

\section{Bae et al [25]}

- Episode triage, timely diagnosis, isolation of patients, and their treatment can be largely supported by telemedicine solutions.

\section{Ben Hassen et al [27]}

- Mobile apps can be used by patients, their caregivers, and health care professionals to better monitor and manage patient health status in the context of patient hospitalization. Moreover, such apps are cost-effective, reliable, and safe, providing important economic benefits to hospitals. Overall, they are accepted to a great extent by patients and individuals. 


\section{Bourdon et al [23]}

- The use of telemedicine tools for consultation purposes improved the access to health care services for patients with ophthalmological problems. At the same time, such tools preserved social distancing and sanitary measures.

- Such tools can be used in emergency situations by ophthalmological patients who have limited access to specialized care.

As reported in the textbox, eHealth solutions can be implemented rapidly and can offer essential tools in supporting the COVID-19 pandemic for all stakeholders including citizens, health care providers, policy makers, and governments. The impact of the COVID-19 pandemic goes beyond the illness and deaths that are directly associated with the SARS-CoV-2 pathogen and toward an expanded scope encompassing mental health and several behavioral changes.

However, there are still several areas to explore, such as better geolocation tracking; timely COVID-19 updates; deployment on nonsmartphone platforms; better incidence visualization and prediction; investigation of a much broader range of putative risk factors for COVID-19 outcomes (based on other longitudinal data on lifestyle, diet, genetics, etc); and the integration with clinical systems, digital health literacy, and engagement with mobile apps.

Apps such as the ones presented in these studies can give the research community the opportunity to monitor long term effects of COVID-19; answer questions such as the number of people truly affected, why some people get sicker than others, and how long people can stay immune to the disease; and perform better resource allocation of medical equipment.
In case of future disease outbreaks, the mobile apps already developed for COVID-19 can be valuable tools ready to support people, health care providers, and policy makers. This study can provide a guide for future developers and researchers regarding the current methodological gaps and challenges that need to be addressed to develop well-designed and evaluated apps for similar future circumstances.

\section{Limitations}

We used terms related to mobile apps, mHealth, and mobile phones for our literature search according to the review objectives and did not use related terms such as "telehealth," which might have resulted in an inadvertent omission of studies. Our literature search was conducted in a limited number of bibliographic databases (Pubmed, Scopus, and the WHO's COVID-19 database), which nevertheless have been largely used worldwide. The gray literature was not explored. The interrater reliability between the authors was not assessed. A meta-analysis was not possible due to the heterogeneity of the included studies. For many cases, the quality of the study might not reflect the quality or the effectiveness of the developed mobile app. As such, useful and effective apps might have not been included in this review study due to the limited quality of the related studies.

\section{Acknowledgments}

This research was supported by the Computational Biomedicine Lab and the Center for eHealth Applications and Services of the Foundation for Research and Technology - Hellas, and the Information Technologies Institute of the Centre for Research and Technology - Hellas.

Work presented in the paper is part of the KRIPIS project "Novel technologies to monitor, support and improve the quality of life of patients and other vulnerable user groups (Quality of Life)" funded in the context of the National Strategic Reference Framework 2014-2020, European Regional Development Fund.

\section{Conflicts of Interest}

None declared.

\section{Multimedia Appendix 1}

PRISMA (Preferred Reporting Items for Systematic Reviews and Meta-Analyses) 2009 checklist. [DOC File, 66 KB-Multimedia Appendix 1]

\section{References}

1. Coronavirus disease 2019 (COVID-19): situation report-78. World Health Organization. 2020 Apr 07. URL: https://www. who.int/docs/default-source/coronaviruse/situation-reports/20200407-sitrep-78-covid-19.pdf [accessed 2020-07-01]

2. Mahmood S, Hasan K, Colder Carras M, Labrique A. Global preparedness against COVID-19: we must leverage the power of digital health. JMIR Public Health Surveill 2020 Apr 16;6(2):e18980 [FREE Full text] [doi: 10.2196/18980] [Medline: 32297868]

3. Triantafyllidis A, Kondylakis H, Votis K, Tzovaras D, Maglaveras N, Rahimi K. Features, outcomes, and challenges in mobile health interventions for patients living with chronic diseases: A review of systematic reviews. Int J Med Inform 2019 Dec;132:103984. [doi: 10.1016/j.ijmedinf.2019.103984] [Medline: 31605884] 
4. Kouroubali A, Koumakis L, Kondylakis H, Katehakis DG. An integrated approach towards developing quality mobile health apps for cancer. In: Moumtzoglou A, editor. Mobile Health Applications for Quality Healthcare Delivery. Hershey, PA: IGI Global; 2019:46-71.

5. Smith AC, Thomas E, Snoswell CL, Haydon H, Mehrotra A, Clemensen J, et al. Telehealth for global emergencies: implications for coronavirus disease 2019 (COVID-19). J Telemed Telecare 2020 Jun;26(5):309-313 [FREE Full text] [doi: 10.1177/1357633X20916567] [Medline: 32196391]

6. Kouroubali A, Kondylakis H, Kavlentakis G, Logothetides F, Stathiakis N, Petrakis Y, et al. An eHealth platform for the holistic management of COVID-19. Stud Health Technol Inform 2020 Sep 04;273:182-188. [doi: 10.3233/SHTI200636] [Medline: $\underline{33087610]}$

7. Katehakis D, Kavlentakis G, Stathiakis N, Logothetidis F, Kouroubali A, Kondylakis H, et al. An outbreak response tool to effectively support surveillance of suspect, probable and confirmed incidence cases while staying safe in COVID-19. 2020 Presented at: 20th IEEE International Conference on Bioinformatics and Bioengineering; October 2020; Virtual conference.

8. Collado-Borrell R, Escudero-Vilaplana V, Villanueva-Bueno C, Herranz-Alonso A, Sanjurjo-Saez M. Features and functionalities of smartphone apps related to COVID-19: systematic search in app stores and content analysis. J Med Internet Res 2020 Aug 25;22(8):e20334 [FREE Full text] [doi: 10.2196/20334] [Medline: 32614777]

9. Davalbhakta S, Advani S, Kumar S, Agarwal V, Bhoyar S, Fedirko E, et al. A systematic review of smartphone applications available for corona virus disease 2019 (COVID19) and the assessment of their quality using the Mobile Application Rating Scale (MARS). J Med Syst 2020 Aug 10;44(9):164 [FREE Full text] [doi: 10.1007/s10916-020-01633-3] [Medline: 32779002]

10. Chamola V, Hassija V, Gupta V, Guizani M. A comprehensive review of the COVID-19 pandemic and the role of IoT, drones, AI, blockchain, and 5G in managing its impact. IEEE Access 2020;8:90225-90265. [doi:

10.1109/access.2020.2992341]

11. Iyengar K, Upadhyaya G, Vaishya R, Jain V. COVID-19 and applications of smartphone technology in the current pandemic. Diabetes Metab Syndr 2020;14(5):733-737 [FREE Full text] [doi: 10.1016/j.dsx.2020.05.033] [Medline: 32497963]

12. García-Iglesias JJ, Martín-Pereira J, Fagundo-Rivera J, Gómez-Salgado J. [Digital surveillance tools for contact tracking of infected persons by SARS-CoV-2]. Rev Esp Salud Publica 2020 Jun 23;94:e202006067 [FREE Full text] [Medline: 32572019]

13. Ekong I, Chukwu E, Chukwu M. COVID-19 mobile positioning data contact tracing and patient privacy regulations: exploratory search of global response strategies and the use of digital tools in Nigeria. JMIR mHealth uHealth 2020 Apr 27;8(4):e19139 [FREE Full text] [doi: 10.2196/19139] [Medline: 32310817]

14. Badawy SM, Radovic A. Digital approaches to remote pediatric health care delivery during the COVID-19 pandemic: existing evidence and a call for further research. JMIR Pediatr Parent 2020 Jun 25;3(1):e20049 [FREE Full text] [doi: 10.2196/20049] [Medline: 32540841]

15. Merchant R, Torous J, Rodriguez-Villa E, Naslund J. Digital technology for management of severe mental disorders in low-income and middle-income countries. Curr Opin Psychiatry 2020 Sep;33(5):501-507. [doi: 10.1097/YCO.0000000000000626] [Medline: 32520747]

16. Santos-Peyret A, Durón RM, Sebastián-Díaz MA, Crail-Meléndez D, Goméz-Ventura S, Briceño-González E, et al. [E-health tools to overcome the gap in epilepsy care before, during and after COVID-19 pandemics]. Rev Neurol 2020 May 01;70(9):323-328 [FREE Full text] [doi: 10.33588/rn.7009.2020173] [Medline: 32329045]

17. Kunz R, Minder M. COVID-19 pandemic: palliative care for elderly and frail patients at home and in residential and nursing homes. Swiss Med Wkly 2020 Mar 23;150:w20235. [doi: 10.4414/smw.2020.20235] [Medline: 32208497]

18. Pan X. Application of personal-oriented digital technology in preventing transmission of COVID-19, China. Ir J Med Sci 2020 Nov;189(4):1145-1146 [FREE Full text] [doi: 10.1007/s11845-020-02215-5] [Medline: 32219674]

19. Chidambaram S, Erridge S, Kinross J, Purkayastha S, PanSurg Collaborative. Observational study of UK mobile health apps for COVID-19. Lancet Digit Health 2020 Aug;2(8):e388-e390 [FREE Full text] [doi: 10.1016/S2589-7500(20)30144-8] [Medline: 32835196]

20. COVID-19: global literature on coronavirus disease. World Health Organization. 2020. URL: https://search.bvsalud.org/ global-literature-on-novel-coronavirus-2019-ncov/ [accessed 2020-11-01]

21. Armijo-Olivo S, Stiles C, Hagen N, Biondo P, Cummings G. Assessment of study quality for systematic reviews: a comparison of the Cochrane Collaboration Risk of Bias Tool and the Effective Public Health Practice Project Quality Assessment Tool: methodological research. J Eval Clin Pract 2012 Feb;18(1):12-18. [doi: 10.1111/j.1365-2753.2010.01516.x] [Medline: 20698919]

22. Moher D, Liberati A, Tetzlaff J, Altman DG, PRISMA Group. Preferred Reporting Items for Systematic Reviews and Meta-Analyses: the PRISMA statement. PLoS Med 2009 Jul 21;6(7):e1000097 [FREE Full text] [doi: 10.1371/journal.pmed.1000097] [Medline: 19621072]

23. Bourdon H, Jaillant R, Ballino A, El Kaim P, Debillon L, Bodin S, et al. Teleconsultation in primary ophthalmic emergencies during the COVID-19 lockdown in Paris: experience with 500 patients in March and April 2020. J Fr Ophtalmol 2020 Sep;43(7):577-585 [FREE Full text] [doi: 10.1016/j.jfo.2020.05.005] [Medline: 32564983] 
24. Huckins JF, daSilva AW, Wang W, Hedlund E, Rogers C, Nepal SK, et al. Mental health and behavior of college students during the early phases of the COVID-19 pandemic: longitudinal smartphone and ecological momentary assessment study. J Med Internet Res 2020 Jun 17;22(6):e20185 [FREE Full text] [doi: 10.2196/20185] [Medline: $\underline{32519963]}$

25. Bae YS, Kim KH, Choi SW, Ko T, Jeong CW, Cho B, et al. Information technology-based management of clinically healthy COVID-19 patients: lessons from a living and treatment support center operated by Seoul National University Hospital. J Med Internet Res 2020 Jun 12;22(6):e19938 [FREE Full text] [doi: 10.2196/19938] [Medline: 32490843]

26. Drew D, Nguyen L, Steves C, Menni C, Freydin M, Varsavsky T, COPE Consortium. Rapid implementation of mobile technology for real-time epidemiology of COVID-19. Science 2020 Jun 19;368(6497):1362-1367 [FREE Full text] [doi: 10.1126/science.abc0473] [Medline: 32371477]

27. Ben Hassen H, Ayari N, Hamdi B. A home hospitalization system based on the Internet of Things, Fog computing and cloud computing. Inform Med Unlocked 2020;20:100368 [FREE Full text] [doi: 10.1016/j.imu.2020.100368] [Medline: $\underline{32537483}$ ]

28. Kodali P, Hense S, Kopparty S, Kalapala G, Haloi B. How Indians responded to the Arogya Setu app? Indian J Public Health 2020 Jun;64(Supplement):S228-S230 [FREE Full text] [doi: 10.4103/ijph.IJPH 499 20] [Medline: 32496261]

29. Medina M, Babiuch C, Card M, Gavrilescu R, Zafirau W, Boose E, et al. Home monitoring for COVID-19. Cleve Clin J Med 2020 Jun 11:1 [FREE Full text] [doi: 10.3949/ccjm.87a.ccc028] [Medline: 32409432]

30. Menni C, Valdes A, Freidin M, Sudre CH, Nguyen LH, Drew DA, et al. Real-time tracking of self-reported symptoms to predict potential COVID-19. Nat Med 2020 Jul;26(7):1037-1040. [doi: 10.1038/s41591-020-0916-2] [Medline: 32393804]

31. Ros M, Neuwirth L. Increasing global awareness of timely COVID-19 healthcare guidelines through FPV training tutorials: portable public health crises teaching method. Nurse Educ Today 2020 May 21;91:104479 [FREE Full text] [doi: 10.1016/j.nedt.2020.104479] [Medline: 32473497]

32. Timmers T, Janssen L, Stohr J, Murk JL, Berrevoets MAH. Using eHealth to support COVID-19 education, self-assessment, and symptom monitoring in the Netherlands: observational study. JMIR mHealth uHealth 2020 Jun 23;8(6):e19822 [FREE Full text] [doi: 10.2196/19822] [Medline: $\underline{\text { 32516750] }}$

33. Yamamoto K, Takahashi T, Urasaki M, Nagayasu Y, Shimamoto T, Tateyama Y, et al. Health observation app for COVID-19 symptom tracking integrated with personal health records: proof of concept and practical use study. JMIR mHealth uHealth $2020 \mathrm{Jul}$ 06;8(7):e19902 [FREE Full text] [doi: 10.2196/19902] [Medline: 32568728]

34. Zamberg I, Manzano S, Posfay-Barbe K, Windisch O, Agoritsas T, Schiffer E. A mobile health platform to disseminate validated institutional measurements during the COVID-19 outbreak: utilization-focused evaluation study. JMIR Public Health Surveill 2020 Apr 14;6(2):e18668 [FREE Full text] [doi: 10.2196/18668] [Medline: 32250958]

35. Parker MJ, Fraser C, Abeler-Dörner L, Bonsall D. Ethics of instantaneous contact tracing using mobile phone apps in the control of the COVID-19 pandemic. J Med Ethics 2020 Jul;46(7):427-431 [FREE Full text] [doi:

10.1136/medethics-2020-106314] [Medline: 32366705]

36. Crico C, Renzi C, Graf N, Buyx A, Kondylakis H, Koumakis L, et al. mHealth and telemedicine apps: in search of a common regulation. Ecancermedicalscience 2018;12:853 [FRE Full text] [doi: 10.3332/ecancer.2018.853] [Medline: 30079115]

37. Kondylakis H, Koumakis L, Hänold S, Nwankwo I, Forgó N, Marias K, et al. Donor's support tool: enabling informed secondary use of patient's biomaterial and personal data. Int J Med Inform 2017 Jan;97:282-292. [doi: 10.1016/j.ijmedinf.2016.10.019] [Medline: 27919386]

\author{
Abbreviations \\ EPHPP: Effective Public Health Practice Project \\ mHealth: mobile health \\ PRISMA: Preferred Reporting Items for Systematic Reviews and Meta-Analyses \\ WHO: World Health Organization
}

Edited by G Fagherazzi; submitted 03.08.20; peer-reviewed by I Zamberg, P Grace-Farfaglia; comments to author 09.09.20; revised
version received 18.09.20; accepted 11.10.20; published 09.12.20
Please cite as:
Kondylakis H, Katehakis DG, Kouroubali A, Logothetidis F, Triantafyllidis A, Kalamaras I, Votis K, Tzovaras D
COVID-19 Mobile Apps: A Systematic Review of the Literature
J Med Internet Res 2020;22(12):e23170
URL: $\underline{\text { http://www.jmir.org/2020/12/e23170/ }}$
doi: $\underline{10.2196 / 23170}$
PMID: $\underline{3197234}$


CHaridimos Kondylakis, Dimitrios G Katehakis, Angelina Kouroubali, Fokion Logothetidis, Andreas Triantafyllidis, Ilias Kalamaras, Konstantinos Votis, Dimitrios Tzovaras. Originally published in the Journal of Medical Internet Research (http://www.jmir.org), 09.12.2020. This is an open-access article distributed under the terms of the Creative Commons Attribution License (https://creativecommons.org/licenses/by/4.0/), which permits unrestricted use, distribution, and reproduction in any medium, provided the original work, first published in the Journal of Medical Internet Research, is properly cited. The complete bibliographic information, a link to the original publication on http://www.jmir.org/, as well as this copyright and license information must be included. 